\title{
La escuela rural, un espacio socialmente construido de posible resistencia territorial: miradas del territorio desde el papel de una docente rural ${ }^{*}$
}

\section{The Rural School, a Socially Constructed Space of Possible Territorial Resistance: Views of the \\ Territory from the Role of a Rural Teacher}

A escola rural, um espaço socialmente construido de possineis resistências territoriais: olhares do território a partir do papel de uma professora rural

\section{Francy Yulieth Gómez Tocarruncho* ${ }^{*}$ Edier Hernán Bustos Velazco ${ }^{* \star *}$ Jaime Duván Reyes Roncancio ${ }^{* \star * *}$}

Recibido: 30 de abril del 2020

Aprobado: 24 de noviembre del 2020

https://doi.org/10.12804/revistas.urosario.edu.co/territorios/a.9032

Para citar este artículo:

Gómez Tocarruncho, F., Bustos Velazco, E., \& Reyes Roncancio, J. (2021). La escuela rural, un espacio socialmente construido de posible resistencia territorial: miradas del territorio desde el papel de una docente rural. Territorios, (44 Especial), 59-85. https://doi.org/10.12804/revistas.urosario.edu.co/ territorios/a.9032

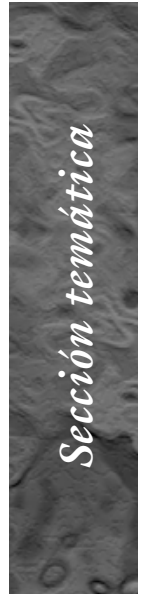

* El presente articulo hace parte de la investigación La escuela un escenario de resistencia territorial. Caso Institución Educativa Rural Mochuelo Alto, de la Maestría en Educación de la Universidad Distrital Francisco José de Caldas. Grupo de investigación INVESTUD de la misma institución

** Universidad Distrital Francisco José de Caldas. Correo electrónico: $l i$ cenciadafrancy@gmail. com ORCID: https://orcid. org/0000-0001-6329-1907 *** Universidad Distrital Francisco José de Caldas. Correo electrónico: ehbustosv@udistrital.edu.co ORCID: https://orcid. org/0000-0003-0072-8598 **** Universidad Distrital Francisco José de Caldas. Correo electrónico: jdreyesr@udistrital.edu. co ORCID: https://orcid. org/0000-0002-9229-1196 
Palabras clave

Territorio; comunidad; escuela rural; educación; co-construcción.

Keywords

Territory; community; rural school; education; co-construction.

Palavras-chave

Território; comunidade; escola rural; educação e coconstrução.

\section{territorias 44 Especial}

RESUMEN

La experiencia de trabajar asuntos relacionados con la educación y categorías de la geografía desde el enfoque de inteligencia territorial, genera reflexiones acerca de la conciencia del lugar y produce diversas lecturas territoriales que inciden en la transformación de las relaciones entre las comunidades que integran la población escolar y la comunidad rural. En este caso, el trabajo de co-construcción participativa con diversos actores de la comunidad educativa desde la zona rural de la localidad de Ciudad Bolívar, en Bogotá, y más concretamente, en la Institución Educativa Distrital Rural Mochuelo Alto, propendió por comprender las diversas territorialidades que allí se conjugan, alrededor del desarrollo de una mesa territorial en la que se generó una propuesta de agenda para transformar situaciones propias del territorio que beneficien a la comunidad.

\section{Abstract}

The experience of working issues related with education and geography categories from the Territorial Intelligence approach, produces some reflections about the place consciousness and also several territorial lectures that influence the transformation of the relationship between the communities who conform school population and the rural community. In this case, the co-construction participative work with several educational community actors from the rural area of the "localidad Ciudad Bolívar" in Bogotá, -concretely- in the district educational rural institution Mochuelo Alto, tried to understand the diverse territorialities that take place there, around a "territorial table" in which an agenda proposal was generated to transform specific situations of the territory that benefits the community.

\section{RESUMO}

A experiência de trabalhar questões relacionadas à educação e categorias da geografia na perspectiva da Inteligência Territorial, gera reflexões sobre a consciência do lugar e produz diversas leituras territoriais que influenciam na transformação das relações entre as comunidades que compõem a população escolar e a comunidade rural. Neste caso, o trabalho de coconstrução participativa com diversos atores da comunidade educativa da zona rural da localidade de Ciudad Bolívar, em Bogotá e mais especificamente, da instituição de ensino Distrital Rural Mochuelo Alto, buscou compreender as diversas territorialidades que ali se combinam, em torno do desenvolvimento de uma mesa territorial onde se gerou uma proposta de agenda para transformar situações próprias do território que beneficiem a comunidade. 


\section{Contextualización territorial}

Este artículo reflexiona sobre la escuela rural como un espacio socialmente construido (Bustos Velazco \& Molina Andrade, 2019). Comienza por reconocer algunas experiencias de comunidades latinoamericanas que han surgido en respuesta o resistencia a circunstancias de orden social, cultural, económico, político, de injusticia y abuso del poder. Ejemplos de lo anterior son el caso de México con la pedagogía de los caracoles y las abejas en el territorio de Chiapas, junto con el proceso autónomo que emprendió el Ejercito Zapatista de Liberación Nacional (EZLN); el Movimiento Sin Tierra (MST) de Brasil; y, en el ámbito nacional, el Consejo Regional Indígena del Cauca (CRIC). Cada una de estas experiencias está acompañada de una lucha que se arraiga en la identidad indígena, campesina y trabajadora.

Discutir sobre la escuela rural en Colombia como un escenario de resistencia territorial, nos lleva a realizar una investigación en el corregimiento de Mochuelo, ubicado dentro de la zona rural de la localidad 19 de Bogotá (Ciudad Bolívar). El corregimiento de Mochuelo se ha caracterizado históricamente como un territorio de tradición campesina, con una economía ligada a la agricultura, a la crianza y el cuidado de animales para la producción de lácteos y carnes. En la actualidad, posee grandes terrenos destinados a la industria extractivista minera y al depósito de basuras de la ciudad.
Dicho corregimiento, con sus veredas Mochuelo Alto y Mochuelo Bajo, se integra a la localidad de Ciudad Bolívar como resultado de las transformaciones que tiene la ciudad de Bogotá en las décadas de 1940 y 1950, cuando la violencia produjo el desplazamiento forzado de la población que llegó a la capital y, por lo general, ocupa las zonas periféricas para el asentamiento de viviendas. En 1983, se concibió para la ciudad el Plan Ciudad Bolivar, el cual tenía como propósito reducir la brecha de pobreza y desigualdad entre la población ubicada en la localidad 19 y el resto de la ciudad, proporcionando recursos para construcción de vivienda, educación y atención de salud. No obstante, la realización de las obras duró mucho tiempo y la ejecución del plan no se llevó a cabo como se había planeado. Frente a las zonas rurales había también una intención:

[...] el Plan Ciudad Bolívar, con el cual se pretendía 'orientar el crecimiento de la Ciudad preservando el espacio de la sabana para fines útiles agropecuarios', propiciando la expansión urbana hasta zonas de menor adaptación agropecuaria cuya utilidad estaría vinculada a los procesos de urbanización, constituyéndose en un ambicioso proyecto urbano, social, e interinstitucional, que involucraba prácticamente a todas las entidades del Distrito (Alcaldía Mayor de Bogotá, s.f., párr. 3). tersitarias 44 Especial

LA ESCUELA RURAL, UN ESPACIO SOCIALMENTE CONSTRUIDO DE POSIBLE RESISTENCIA TERRITORIAL 
De esta manera, se incorporaron al proyecto de localidad nueve veredas: Las Mercedes, Santa Bárbara, Santa Rosa, Pasquillita, Pasquilla, Mochuelo Alto, Mochuelo Bajo, Quiba Alta y Quiba Baja. El espacio ocupado se pensó como una gran extensión de tierra proyectada para usos agrícolas y pecuarios que superaría el porcentaje de espacio ocupado por suelo urbano.

En la actualidad, antes de ascender a la zona de Mochuelo, sobre la vía principal se hallan varias fábricas de ladrillo y material para construcción, una industria que también se encuentra presente entre las veredas de Mochuelo Bajo y Mochuelo Alto. Paralelamente, el Relleno Sanitario Doña Juana (RSDJ) ha desencadenado diferentes situaciones contaminantes que generan problemas para la salud de los pobladores del corregimiento (Mochuelo), afectando el medio ambiente y la ciudadanía en general.

Teniendo en cuenta las características histórico-espaciales de Ciudad Bolívar y del corregimiento de Mochuelo, es importante aclarar que en la investigación sobre la Escuela Rural de Mochuelo Alto como escenario de resistencia, los términos de espacio y territorio se entienden siguiendo los planteamientos de Milton Santos (2000):

[...] el espacio no es ni una cosa ni un sistema de cosas, sino una realidad relacional: cosas y relaciones juntas. Por esto su definición solo puede situarse en relación a otras realidades: la naturaleza y la sociedad, mediatizadas por el trabajo. Por lo tanto, no es, como las definiciones clásicas de geografía, el resultado de una interacción entre el hombre y la naturaleza bruta, ni siquiera de una amalgama formada por la sociedad de hoy y el medio ambiente. El espacio debe considerarse como el conjunto indisociable del que participan, por un lado, cierta disposición de objetos geográficos, objetos naturales y objetos sociales, y por otro, la vida que los llena y anima, la sociedad en movimiento. El contenido (de la sociedad) no es independiente de la forma (los objetos geográficos); cada forma encierra un conjunto de formas, que contienen fracciones de la sociedad en movimiento. Las formas, pues, tienen un papel en la realización social (Santos, 2000, pp. 26-27).

Si se entiende así el concepto de espacio, resulta interesante cuestionarse sobre las relaciones que se generan entre diferentes espacios (diversas realidades), es decir, ¿quiénes los ocupan?, ¿cómo son ocupados?, ¿qué relaciones se construyen en y entre ellos? y ¿cuáles dificultades se encuentran en su construcción? En ese mismo sentido, es relevante el concepto de territorio que va de la mano con el de espacio emergente, entendiéndose el primero como la propiedad o apropiación que, en el panorama actual (globalizante) trae consigo una relación entre los ejes de poder y las formas de administrarse y habitarse el espacio. Estas se muestran 
como resultado de los cambios globales en las relaciones humanas y económicas, así como en el esfuerzo de los entes políticos para entenderlos y tratarlos.

\section{Mochuelo Alto: intersticio en el territorio de Ciudad Bolívar}

Con el propósito de acercarse a la escuela como probable espacio de las resistencias territoriales, es pertinente situarse en el territorio y estudiar sus dimensiones. En este caso, la investigación-acción realizada con un enfoque de inteligencia territorial, se fundamentó en el método Territorii (Bozzano, 2009b).

El enfoque de inteligencia territorial, que surge como un trabajo multidisciplinar, permite una hábil combinación con la estructura y herramientas que brinda la investigación acción con el método $T e$ rritorii; el cual consiste en "una mirada territorial a proyectos e investigaciones no siempre territoriales" (Bozzano, 2009a, p. 4). Así, situarse en el territorio refiere a comprender la escuela rural a partir de las cinco dimensiones o criterios explicados por Bozzano y a un acto reflexivo que debe ser empático con la comprensión de las dinámicas del territorio.

Las categorías propuestas por Bozzano (2009a, p. 5) en el método Territorii, a saber: territorios reales, territorios vividos, territorios pensados, territorios legales y territorios posibles, se emplean para comprender la construcción del concepto de escuela rural y desde allí ir develando las relaciones que se tejen entre las comunidades de la vereda y de la institución educativa. Es necesario que las distintas territorialidades que integran a la comunidad educativa sean tenidas en cuenta, ya que la escuela rural es un lugar que sirve como punto de encuentro entre niños, niñas y familias de la zona periurbana (figura 1), las veredas altas del corregimiento y la zona urbana de la localidad de Ciudad Bolívar.

De este modo, los territorios reales son aquellos que se configuran desde lo descriptivo, los fenómenos y una realidad aceptada por la comunidad científica que la denomina bajo conceptos y términos aprobados por esta. Los territorios vividos son muestra de la percepción de quienes viven los territorios. Los territorios pensados se construyen con la finalidad de explicar la realidad, sin la necesidad de una aprobación por parte de una comunidad científica, podría decirse que son el resultado de la manera en que los habitantes del territorio observan y comprenden los procesos que en este ocurren. Los territorios legales responden a especificidades sobre el deber ser de los territorios en el marco de lo legal. Los territorios posibles son la posibilidad o posibilidades de transformación que surgen del diálogo entre el concreto real de los territorios reales y el concreto pensado de los territorios pensados (Bozzano, 2009a, p. 5).

La caracterización de la vereda $\mathrm{Mo}^{-}$ chuelo Alto contempla las dinámicas propias de la institución educativa y el Relleno Sanitario Doña Juana (RSDJ). Así que, territorios 44 Especial 
${ }^{1}$ Corregimiento departamental: es una división del departamento, la cual incluye un núcleo de población. Según esta misma norma, los ahora corregimientos departamentales no forman parte de un determinado municipio. De conformidad con el Decreto 2274 de 1991 (octubre 4). Instituto Geográfico Agustin Codazzi. https:// www.igac.gov.co/es/contenido/areas-estrategicas/ fronteras-y-limites-deentidades-territoriales

\section{territarios 44 Especial}

Figura 1. Vista desde el salón de clase 1-B, Colegio Rural Mochuelo Alto

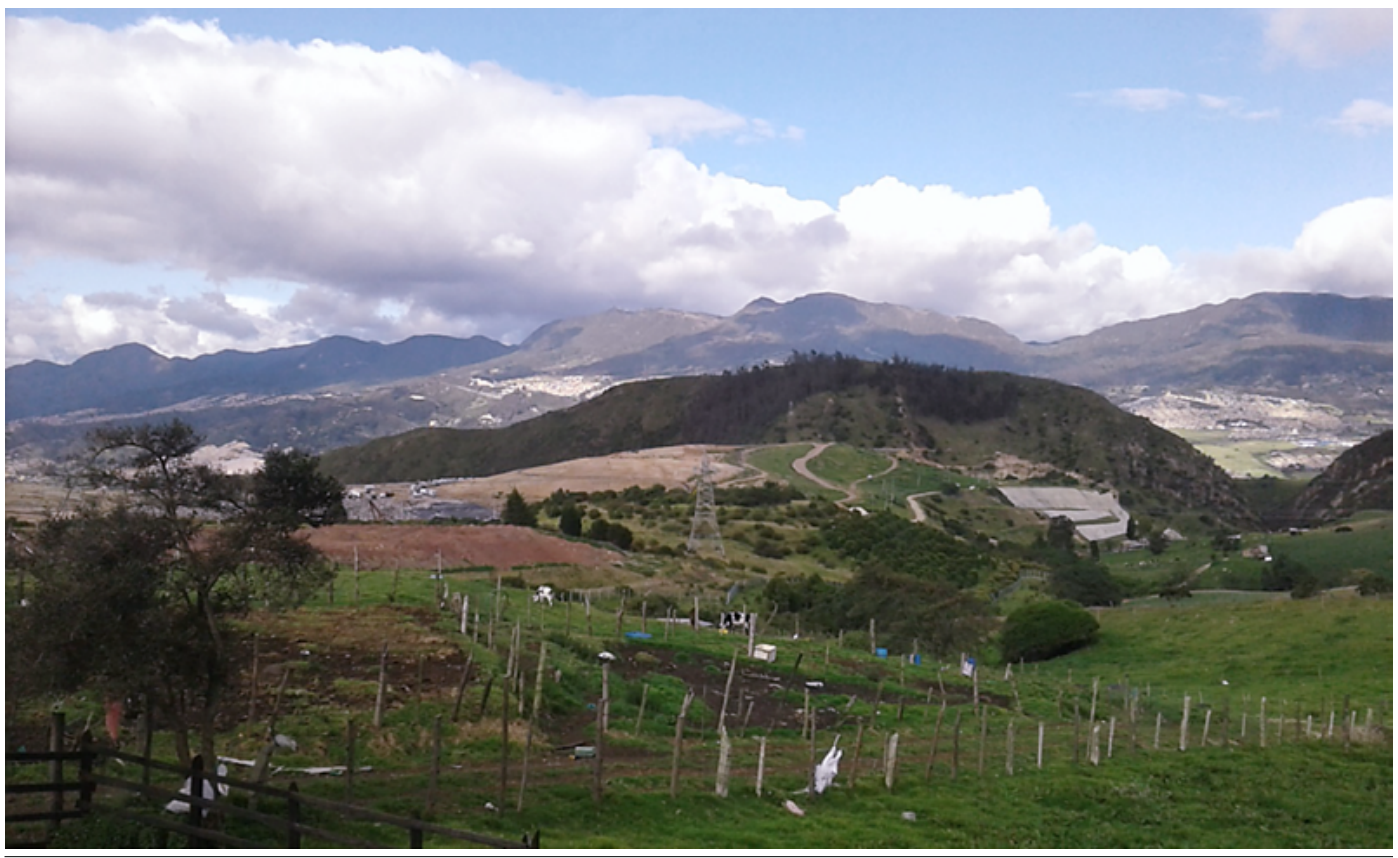

Fuente: elaboración propia.

a través de un análisis de contenido teniendo en cuenta los criterios construidos por Bozzano en el método Territorii, y empleando el software Atlas-ti ${ }^{\circledR}$, se ponen en diálogo: la información obtenida del trabajo de campo (entrevistas semiestructuradas, talleres de mapeo, talleres de representación gráfica sobre territorio, encuentros con niños y niñas de la vereda y una mesa de trabajo territorial), con los documentos consultados para la construcción del marco teórico de esta investigación, usando como punto de encuentro los criterios del pensar situada la escuela rural planteados por (Bozzano, 2017).
Mochuelo Alto es una vereda que hace parte del corregimiento ${ }^{1}$ de Mochuelo, está a 3200 m.s.n.m. y posee un centro poblado según el Plan Ambiental Local (2013-2016):

Mochuelo Alto: con un área total de 1455,07 hectáreas y un $15,14 \%$ de participación sobre el suelo rural de la localidad, la vereda limita al norte con el área urbana de la Localidad de Ciudad Bolívar y la Vereda de Mochuelo Bajo, al occidente con la Vereda de Quiba Alta, al sur con la Vereda Pasquilla y al oriente con el área urbana la Localidad (pp. 16-17). 
Como la mayoría de veredas de la zona, su fundación se remonta al encuentro entre vecinos con el fin de construir la iglesia de la vereda. El terreno lo donó don Manuel Castiblanco, pero fue el señor Pompilio Beltrán quien hizo toda la gestión para recoger donaciones entre los habitantes y, finalmente, el señor Ismael Montaña la construyó. En ese espacio, como producto del encuentro entre la comunidad, se fundó un pequeño centro poblado que en la actualidad no solo está ocupado por la iglesia, sino por el salón comunal, la escuela, el centro de salud y unas pocas manzanas en las que se encuentran algunos negocios como panaderías, papelerías, carnicerías, ventas de productos lácteos, restaurantes, entre otros.

De 1951 a 1953 se pavimentó la vía que comunica el corregimiento de Mochuelo a Pasquilla. Vía principal que hasta la década del cuarenta fue camino de herradura y, que hoy día cobra gran importancia, puesto que conecta la zona rural de Ciudad Bolívar con la urbana; además, es el paso obligado de camiones que transportan papa, zanahoria, habas, arveja, nabo y fresas hacía la plaza de Corabastos ${ }^{2}$ en la ciudad de Bogotá.

La Alcaldía Mayor de Bogotá bajo el mandato de Enrique Peñaloza, se pronunció acerca de la zona rural de Bogotá y, de manera más específica, sobre Mochuelo Alto en dos de los apartados del proyecto Plan de Ordenamiento Territorial (POT) del Plan de Gobierno de la ciudad: Bogotá Mejor para Todos.
El proyecto de acuerdo al Plan de Ordenamiento Territorial de Bogotá, en el Artículo 26 dispone:

[...] se soporta en una red de asentamientos humanos rurales, áreas protegidas y áreas productivas que se articulan para la protección del paisaje característico de la ruralidad bogotana y en el Sistema de Movilidad adecuado para el transporte de personas y mercancías en las zonas rurales que permiten la adecuada conectividad e integración territorial, en donde la economía campesina familiar y la conservación de los ecosistemas alto andinos representan valores de protección (p. 12).

El apartado anterior describe de manera concreta el territorio. En términos de Bozzano, se señala el territorio legal. No obstante, en la parte final se hacen algunas apreciaciones acerca del carácter del territorio, por ejemplo, cuando se mencionan los "valores de protección" del ambiente y la tradición campesina y familiar. Esto último es una mera opinión acerca de los pobladores y no algo corroborable desde conceptos y estudios etnográficos del territorio, por tanto, vislumbra una intencionalidad de orden político sobre el territorio. El territorio legal, pareciera sobreponerse sobre el territorio real.

En la sección n. ${ }^{\circ} 3$ del proyecto acuerdos del POT, titulada Áreas de conectores ecológicos en el Artículo 81, Mochuelo Alto es mencionada como uno de los corredores ecológicos de la ciudad. Se
2 Corporación de Abastos de Bogotá S.A., es una plaza mayorista situada al occidente de la capital colombiana. tersitarios 44 Especial 
explica además, la función de las áreas de conectores ecológicos y la categoría de corredor ecológico así:

Artículo 81. Categoría de Corredor Ecológico Rural. Son espacios en el suelo rural que tienen como principal vocación el uso forestal, se encuentran inmersos en agroecosistemas campesinos y que, debido a su baja productividad, se caracterizan por su alta vulnerabilidad ante fenómenos de remoción en masa, erosión y escorrentía superficial que afectan la fertilidad del suelo (p. 53).

La literatura que se encuentra sobre el corregimiento y, en especial de Mochuelo Alto, es poca. No obstante, se destaca en los documentos leídos y las páginas visitadas, que la mirada de las zonas rurales se hace desde un componente de tipo ambiental. Lo anterior resulta paradójico para esta zona de la ciudad, puesto que en ella se encuentra una de las fuentes de mayor contaminación: el Relleno Sanitario Doña Juana. Esto permite formular algunos cuestionamientos sobre la veracidad de lo citado en el documento de acuerdos del POT, dado que una lectura juiciosa de este no da cuenta de las realidades del territorio, en específico, de sus características ambientales y ecosistémicas.

A finales de la década de los cuarenta, los niños y niñas de la vereda de Mochuelo Alto debían trasladarse hasta Mochuelo Bajo caminando, ya que en la vereda no se contaba con una institución educativa. Ana
Lucía Rodríguez Gonzáles, en su libro Las raices de Mochuelo, en el capítulo dedicado a la educación, narra cómo, a través de rifas, fiestas, bazares y reinados se construyó el primer salón de clase. Para esa época, la escuela ofrecía solo los grados de primaria. En 1972 se construyó la parte nueva de lo que para ese momento se denominó Centro Educativo Distrital Mochuelo Alto (CEDIMA) (figura 2), compuesta por dos salones más y un apartamento construido para el profesor rural como vivienda. Esta última es una construcción característica de las escuelas rurales, en la cual se alojan los y las docentes que llegan.

En 1983 se hicieron otras reformas a las instalaciones del colegio entre $1980 \mathrm{y}$ el 2010, periodo en el cual la institución tuvo como director rural a Parmenio Hernández, quien amplió la cobertura, por lo que niños y niñas de barrios cercanos, pertenecientes a la zona urbana también llegaron a estudiar en el colegio.

En la actualidad, las familias que hacen parte de la comunidad educativa del Colegio Rural Mochuelo Alto CED, viven en la franja de transición periurbana de la localidad de Ciudad Bolívar, en barrios periféricos pertenecientes al sector de Mochuelo Bajo, tales como Barranquitos, Lagunitas, Paticos; así como de la zona urbana en barrios como Casa de Teja, Divino Niño, Acapulco, San Joaquín y El Rincón; también hay familias que residen en distintos sectores de la vereda, aunque en menor cantidad. 
Figura 2. Entrada al Colegio Rural Mochuelo Alto, iglesia y salón comunal

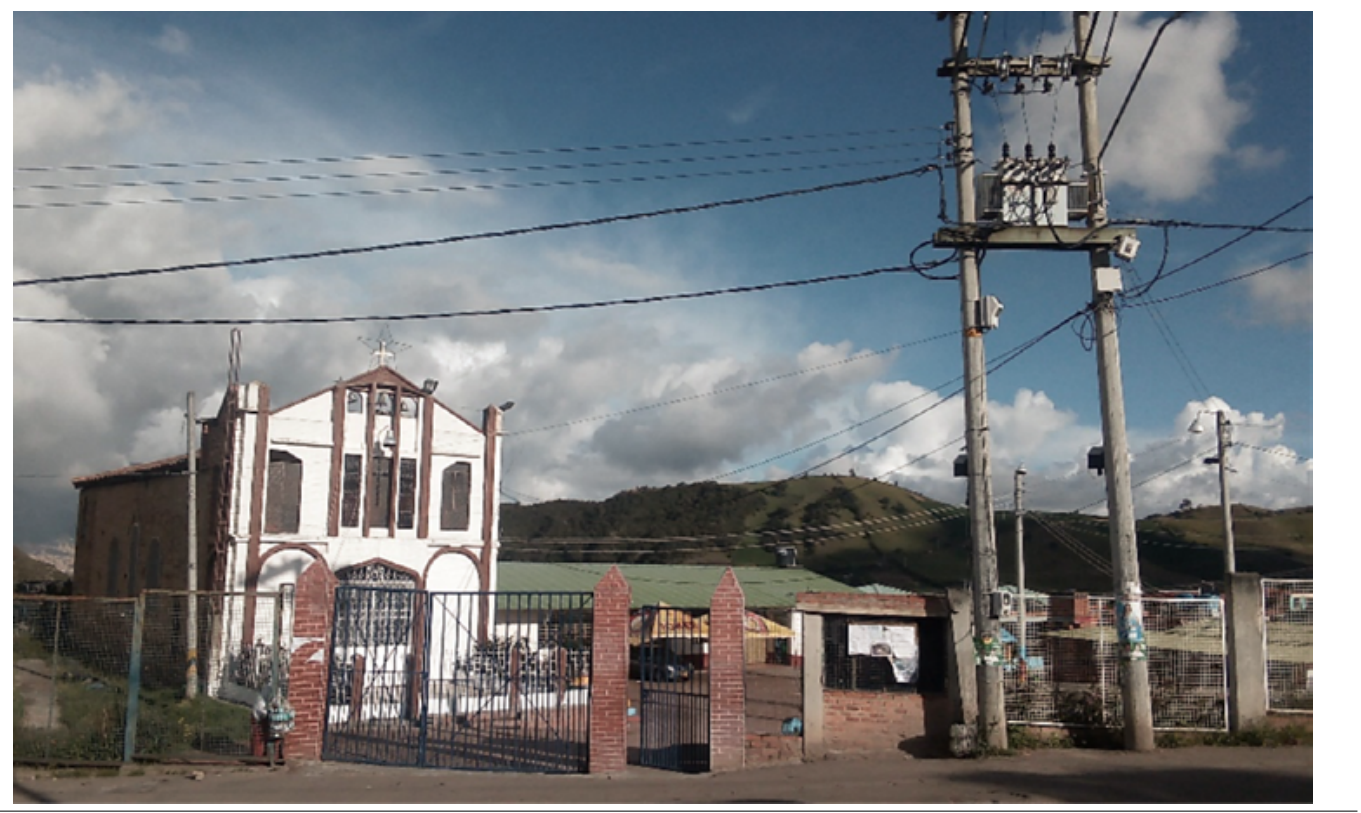

Fuente: elaboración propia.

La institución se encuentra ubicada en el kilómetro 24 vía Pasquilla, hace parte del sector oficial, es calendario A, posee jornada única, ofrece los niveles de preescolar, básica primaria y, adelanta un grupo de aceleración y formación para adultos durante los fines de semana. El director rural actual, Mauricio Pedraza, presentó una caracterización correspondiente al 2017, en la que menciona las carencias y necesidades de la población en servicios básicos, así como las afectaciones en el área de la salud, muchas de ellas consecuencia de la cercanía con el relleno sanitario, como sigue: solamente el 10,2\% de las familias manifiestan tener una alimentación sana rica en fibra y proteína, el 10,2\% dicen solo consumir carbohidratos y se ha observado en diferentes ocasiones que un $30 \%$ de los estudiantes se presentan al colegio sin desayunar. El 39\% de niños y niñas están en riesgo de bajo peso según informe de equipo Sisbén -Secretaría de Salud a partir de toma de talla y peso realizado en el mes de julio del presente año. El $25 \%$ de los estudiantes poseen necesidades educativas especiales y solo $40 \%$ de ellos y ellas presentan diagnóstico; esta condición está directamente relacionada con la mala nutrición, la proximidad al botadero de basura territarios 44 Especial 


\section{territorias}

\section{Especial}

y la falta de estimulación en la primera infancia [sic] (Pedraza, 2017, p. 2).

El título del Proyecto Institucional de Educación Rural (PIER) de la institución, es Mi Escuela Rural Mochuelo Alto conoce $y$ transforma nuestro territorio. Dentro de los principios institucionales, tiene como misión educadora fortalecer procesos de pensamiento crítico y creativo en los niños y las niñas desde el reconocimiento de los saberes del territorio rural y urbano mediante el enfoque de la educación popular, con el apoyo de la metodología por proyectos y el modelo de escuela nueva activa, como una forma de fortalecer los proyectos de vida de los estudiantes y de sus familias para generar un ambiente escolar participativo, afectivo y transformador de su entorno.

La propuesta que se desarrolla en el PIER de la institución apunta a consolidar una formación socio-crítica, reconoce las diversas condiciones y realidades de quienes integran la comunidad educativa, tiene presente la ubicación geográfica de la institución, y por ello, considera vital la formación en valores ético-ambientales y un trabajo constante de construcción con la comunidad.

\section{Relleno Sanitario Doña Juana: espacio confinado al detrimento del ambiente y del territorio rural}

El vertedero de basuras de la ciudad de Bogotá se encuentra ubicado entre la zona urbana y rural de las localidades de Usme y Ciudad Bolívar, en la margen izquierda del río Tunjuelo y en el corregimiento de Mochuelo. En 1984, la Corporación Autónoma Regional (CAR) contrató a Ingesam-URS, quienes definieron y dispusieron el diseño del sitio al que finalmente llegarían los residuos sólidos de la ciudad y de algunos municipios cercanos tales como Soacha, Funza, Mosquera y Madrid. Desde entonces, ha habido varias empresas de operaciones que se han encargado de los diseños de funcionamiento y ampliación del relleno, todas, desde luego, acompañadas por entidades del gobierno local de la ciudad. En la actualidad, el Centro de Gerenciamiento de Residuos (CGR) Doña Juana E.S.P. S.A., es quien lo opera. Cabe resaltar que el botadero tiene vida útil hasta el 2022.

La Secretaría de Ambiente, en el Plan Ambiental Local (2013-2016) que presentó para el periodo 2012-2015 hace un amplia descripción de las zonas del vertedero y su localización:

El relleno sanitario Doña Juana se localiza entre los 2715 y 2800 m.s.n.m., en la cuenca del río Tunjuelo, siendo la autopista a Villavicencio, la principal vía de acceso, comprende un área en funcionamiento en suelo rural aproximada de 303,78 ha, ubicadas en la Localidad de Ciudad Bolívar en las Veredas Mochuelo Alto (186,90 ha) y Mochuelo Bajo (116,88 ha), cuenta con un área de reserva para la disposición de 
residuos de 269,50 ha situadas en la Vereda Quiba Baja (p. 21).

Recientemente, el Ministerio de Ambiente y Desarrollo sostenible emitió la Resolución 1484, en donde se indica quiénes deben hacer el seguimiento, evaluación y control del proyecto Relleno sanitario Doña Juana. Allí se determinan a la CAR de Cundinamarca y a la Autoridad Nacional de Licencias Ambientales (ANLA) como responsables de estas labores.

El Grupo Epidemiología y Salud Poblacional (2006) conformado por investigadores de la Universidad del Valle, escribieron un informe sobre el proceso de evaluación que se desarrolló durante el 2006, acerca del impacto del RSDJ en la salud de grupos poblacionales en su área de influencia. En el informe final:

Los resultados de la evaluación realizada muestran impactos en las condiciones ambientales y de salud medidas de manera objetiva y subjetiva. No obstante, estos impactos deben ser comprendidos en el marco de las desventajas históricas socioeconómicas en las que viven las poblaciones aledañas al RSDJ. En el estudio se evaluaron y cuantificaron los efectos de la exposición en la salud de la población, encontrándose que ello está en parte mediado por variables relacionadas con la condición socioeconómica (ingreso, afiliación al Sistema General de Seguridad Social en Salud, condiciones de la vivienda, nivel educativo) y la presencia de ladrilleras, lo cual muestra una conglomeración de factores de riesgo que hacen a la población residente en la zona de Mochuelo Alto y Bajo más vulnerable frente al RSDJ (Méndez et al., p. 7).

Es cuestionable el tipo de seguimiento a las operaciones de Doña Juana dado el conjunto de evidencias acerca de los impactos en la salud de grupos poblacionales del área de influencia que se reportan en el informe final presentado a Proactiva Doña Juana E.S.P. S.A., con el acompañamiento de la Secretaría de Salud Distrital de Bogotá durante el 2006, los monitoreos realizados por la Secretaría de Salud, los informes más recientes del 2018, el 2019 y los informes presentados por la Contraloría y Personería de Bogotá en sus páginas web. ${ }^{3}$

La gestión territorial latinoamericana, en particular la colombiana, se ha centrado en lo urbano fomentando la inequidad en los territorios rurales. De esta manera, son diversos los mecanismos por los cuales se ha subalternizado a lo rural. Un ejemplo de esta relación desigual es, sin duda, la ubicación de los rellenos sanitarios (Quintero, 2016, p. 270).

A partir del análisis hecho hasta este punto, emerge una nueva categoría de territorio: los territorios ficcionados. Estos territorios son aquellos que se sustentan bajo un marco normativo - el territorio legal-, pero que no presentan congruencia con el territorio real, tampoco con el territorio pensado $\mathrm{y}$, aunque parecieran tener un sustento científico por el apoyo de
${ }^{3}$ Véase en Personería de Bogotá. https://www. personeriabogota.gov. co/buscar?searchword = do 0 C $3 \%$ B 1 a \% 20 juanaesearchphrase $=$ all

\section{territarios 44 Especial}

LA ESCUELA RURAL, UN ESPACIO SOCIALMENTE CONSTRUIDO DE POSIBLE RESISTENCIA TERRITORIAL

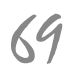


${ }^{4}$ Véase en Lineamientos para la implementación de politicas, programas $y$ proyectos educativos. https://repositoriosed. educacionbogota.edu.co/ bitstream/001/2554/1/ LINEAMIENTOS\% 20 EDUCATIVOS\% 20 $P A R A \% 20 L A \% 20$ BOGOT\%C3\%81\%20 RURAL.pdf

\section{territorias 44 Especial} 70 la norma, no resultan de fácil comprensión para las comunidades de los territorios al no presentar correspondencia con el constructo del territorio real o, la conciencia del lugar ocupado. La idea de territorio ficcionado tiene entonces una característica asociada a los actores, las comunidades y los que ostentan el poder sobre el uso del suelo en el territorio, que consisten en posicionar imaginarios del territorio desde lo normativo en discordancia con las realidades vividas por sus habitantes.

Como territorio legal, la escuela rural no puede aislarse del territorio real que la constituye, ni del territorio vivido. Sin embargo, entra en una tensión constante porque en muchas situaciones no se corresponde lo prescriptivo de las políticas con su ejercicio. Normas o leyes que deben garantizar el cumplimiento efectivo del derecho a la educación de calidad, a la salud, a un ambiente sano y al funcionamiento adecuado del relleno sanitario de la ciudad para el caso del Colegio Rural Mochuelo Alto, son evidentes las siguientes situaciones:

- El acuerdo de la Secretaría de Educación junto a la Secretaría de Desarrollo Económico ${ }^{4}$ para el funcionamiento de unidades hidropónicas, bajo cubierta que da sustento al Artículo 67 de la Ley 115 de 1994, en la que se estableció que, en consonancia con el plan de desarrollo municipal o distrital, en los corregimientos o las inspecciones de policía funcionará una granja integral, o una huerta escolar anexa a uno o varios establecimientos educativos, en donde los educandos puedan desarrollar prácticas agropecuarias y de economía solidaria o asociativa que contribuyan a mejorar su nivel alimentario.

Este acuerdo ha sido suspendido en varias oportunidades y, aunque se han entregado algunos insumos al colegio, no se ha contado con la asesoría técnica, ni los talleres necesarios para hacerse cargo de la unidad, ya que el colegio no tiene docentes profesionales en el área agropecuaria.

- En el diagnóstico comunitario de Ciudad Bolívar publicado por la Defensoría del Pueblo del Territorio en el 2018, el apartado sobre derechos ambientales y colectivos, luego del diagnóstico y análisis de la información aduce: "La vereda Mochuelo presenta riesgo antrópico y contaminación atmosférica, debido a la explotación de canteras, chimeneas de industria, mataderos clandestinos y el Relleno Sanitario Doña Juana, todo lo cual puede generar material particulado y gases además de olores ofensivos" (Defensoría del Pueblo Colombia, 2018, p. 61).

Frente a estas situaciones se han puesto sanciones económicas, pero el relleno sigue funcionando y afectando a la comunidad de la vereda y de la institución educativa rural, no obstante, vale recordar lo que 
se enuncia en el documento del proyecto POT para Bogotá:

[...] Se soporta en una red de asentamientos humanos rurales, áreas protegidas y áreas productivas que se articulan para la protección del paisaje característico de la ruralidad bogotana y en el Sistema de Movilidad adecuado para el transporte de personas y mercancías en las zonas rurales que permiten la adecuada conectividad e integración territorial, en donde la economía campesina familiar y la conservación de los ecosistemas alto andinos representan valores de protección (p. 12).

Los territorios ficcionados emergen como una categoría que, aunque no son la finalidad de la investigación, explican y permiten una mejor comprensión de la incoherencia entre los territorios reales, territorios legales, territorios vividos y territorios pensados (Bozzano, 2012).

La institución educativa rural y el relleno sanitario no son lugares que se puedan aislar de las dinámicas de la vereda Mochuelo Alto desde la mirada territorial, pues sus vínculos son históricos y permanentes.

En el trabajo de grado de Erika Ortiz Díaz, para obtener el título de socióloga de la Universidad del Rosario, llamado Relatos de violencia ambiental: el caso Doña Juana (2016), hay una narración de un habitante de Mochuelo, don Filadelfo, un hombre de 84 años de edad que al describir un poco el contexto del corregimiento en su niñez habla de la escuela, que para ese entonces se ubicaba en lo que hoy en día se conoce como Mochuelo Bajo (Ortiz, 2016): “[...] Hasta ahora es que Mochuelo Alto tiene colegio allá, porque todos bajaban acá a estudiar y de la parte de abajo también subían” (p. 46) y continúa su narración comentando sobre el relleno:

Las tierras de la Juana [...] como eso era de las señoritas Zapatas, de La Fiscala (una hacienda), entonces después ya un abogado [...] ahí había un abogado que se hizo dueño de la hacienda, y entonces ya se murió él y quedó la señora y la señora fue la que vendió ¡No $[\ldots]$ a esa señora si no la conocimos! Porque eso sí fue lo peor que pudo haber hecho, porque si ella no vende eso iJmm! ¡Vendió las mejores tierras! Y para hacernos mal. Ella cogió su plata y chao y vea lo que nos pasó a nosotros.

Las descripciones de la historia, dinámicas y formas de ver el territorio permite comprenderlo, pero es evidente que para este caso no es suficiente abordarlo de manera fragmentada, el papel que cada uno de los lugares mencionados cumple en el espacio es de complementariedad, logrando una completitud que no se puede pasar por alto y que hace necesaria la caracterización o rasgos de sus relaciones para que desde allí se proponga un ejercicio participativo de co-construcción entre las comunidades. 
El Colegio Rural Mochuelo Alto: un territorio de mediación

Las formas en que se narran las diversas miradas y lecturas del territorio permiten percibir sentidos y significados del espacio y de las relaciones o sistemas que interactúan en él. Para el caso de la investigación que aquí se reporta, se desarrolló un trabajo durante el 2019 que permitió, a partir de diferentes actividades como mapeos, entrevistas, cuestionarios y una mesa de trabajo territorial, caracterizar las percepciones que tuvieron las maestras y maestros del Centro Educativo Distrital Rural Mochuelo Alto, la de algunos educandos, la de administrativos y personal de servicios generales, así como de las personas de la comunidad de la vereda sobre el espacio, los lugares, los sujetos y las relaciones que se establecen con el territorio.

Al planear el análisis se tuvo en cuenta todo lo desarrollado en el trabajo de campo (figura 3 ) y la literatura que comprendía los conceptos de espacio, territorio, territorialidad, desterritorialización, conceptos y experiencias de resistencia, miradas y políticas de la educación rural en Colombia, monografías, artículos e investigaciones desarrolladas sobre Mochuelo Alto y de la comprensión del concepto de la escuela rural obtenido del cruce o

Figura 3. Mesa de trabajo territorial

tersitorios 44 Especial

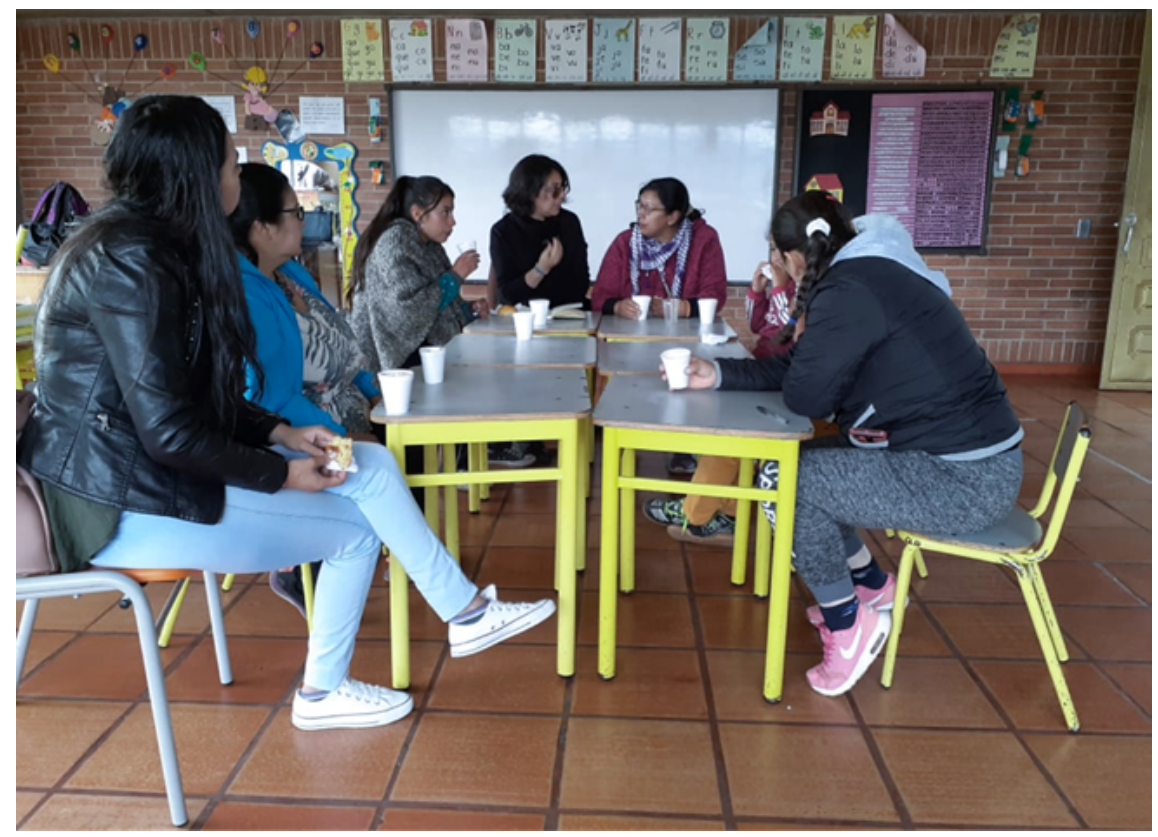

Fuente: elaboración propia. 
relación de información entre los criterios escuela real, escuela vivida, escuela pensada, escuela legal y escuela posible, que se realizó con la ayuda del software Atlas-ti ${ }^{\circledR}$, construyendo unos rasgos o características relacionales.

\section{La escuela como territorio real}

Recoge diferentes críticas sobre los servicios públicos (salud, transporte, agua, recolección y depósito de basuras, luz y gas), realizadas por las comunidades de la vereda y de la institución educativa, generando insatisfacción, tensiones, $y$ a la vez, empatía por las problemáticas compartidas del territorio. Sin embargo, no se generan acciones conjuntas y no hay canales de comunicación efectivos. Así, la escuela como territorio real, se compone de una escuela legal que proporciona unos lineamientos para su funcionalidad desde una política nacional y otra distrital. La escuela real incide en las experiencias o vivencias personales de quienes han pasado por ella. Hace parte de la escuela pensada y de la escuela posible, ya que a partir de las lecturas de su realidad se planifican y proyectan acciones transformadoras. Bajo el criterio de lo real, la escuela rural tiene estrecha relación con el botadero Doña Juana, el servicio de transporte y el servicio de salud de la vereda.

Esta institución educativa se encuentra a una distancia aproximada de 600 metros del RSDJ y a 1,6 km aproximadamente de las ladrilleras más cercanas. En el trabajo de campo, Gálvez y otros docentes manifestaron percibir malos olores durante ciertas horas de la jornada académica y en algunos periodos del año, según las condiciones del tiempo que se estén presentando.

En las entrevistas realizadas (figura 4), las familias de algunos barrios de Mochuelo Bajo y otras que habitan en cercanías al RSDJ en la zona de Mochuelo Alto, como es el caso de la familia Beltrán Cangrejo, manifestaron durante los ejercicios de entrevistas: "El relleno nos ha afectado toda la vida, ha afectado los cultivos, nuestra salud y a los animales, esto a causa de las plagas y vectores como moscas y ratas" (comunicación personal, 16 de octubre del 2019).

El servicio de transporte influye en la cercanía de las familias respecto a las dinámicas de la institución, ya que por quedar en una zona rural - distante-, la frecuencia del transporte público es baja, solo hay una ruta del SITP que llega hasta el colegio, sube hasta la vereda Santa Bárbara en el corregimiento de Pasquilla y se regresa por la misma vía (Ruta 6-18 del SITP).

El grupo de estudiantes con el que se trabajó en los procesos de mapeo, entrevistas y talleres, manifestó que el servicio de transporte es "muy malo" y que ellos "por vivir en el sector" no tienen ruta, así que deben trasladarse a pie desde sus casas. Ahora bien, la Resolución 1795 de 2016 de la Secretaría Distrital de Educación, es clara en su capítulo II frente a tersitarias 44 Especial 
Figura 4. Ejercicio de entrevistas por parte de estudiantes del Colegio Rural Mochuelo Alto a vecinos y vecinas de la comunidad de la vereda Mochuelo Alto

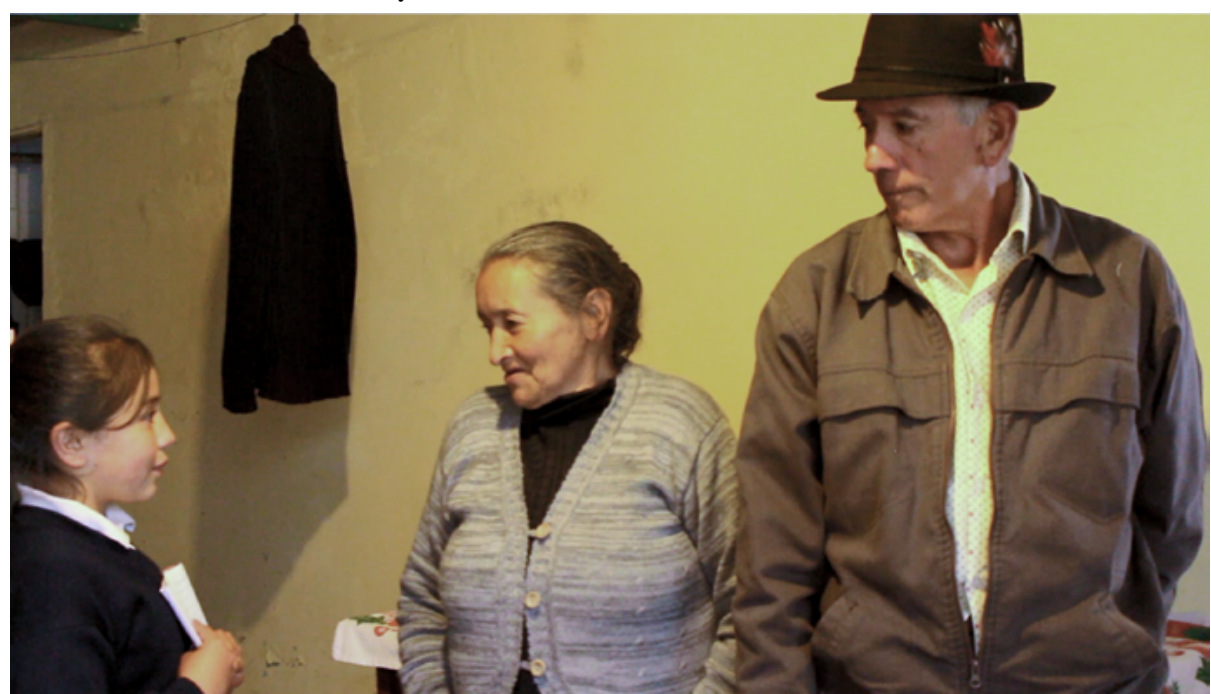

Fuente: elaboración propia.

la definición de ruta escolar, requisitos y criterios de asignación, los cuales están sujetos a la disponibilidad presupuestal. En el artículo octavo de la resolución se habla de casos especiales y se nombra la asignación de rutas para zonas rurales:

b) Rutas para docentes o comunidad educativa que presten sus servicios en sedes de colegios de zonas rurales o urbanas de difícil acceso y/o de inseguridad de acuerdo a solicitud debidamente justificada por la Dirección de Talento Humano de la Secretaría de Educación en los casos de rutas docentes y, para la comunidad educativa autorizados por la Dirección de Bienestar Estudiantil previa solicitud del rector/rectora de la Institución Educativa.
Pese a esto, el servicio solo cubre a quienes suben a la institución educativa, no a quienes bajan, por ejemplo, la docente que desarrolló este trabajo junto con niños y niñas habitantes de sectores como el Alto del Gallo y los Alpes. La Resolución 039 de 2018, unifica los criterios y las condiciones generales del programa de movilidad escolar en sus diferentes modalidades y dispone:

Que la Secretaría de Educación del Distrito, mediante la Resolución 1531 de 2014, modificada por las Resoluciones $151 \mathrm{del}$ 28 de enero de 2015 y 1795 del 3 de octubre de 2016, reglamentó la operación del Programa de Movilidad Escolar en sus diferentes modalidades, estableciendo los 
requisitos y los criterios para su asignación. Que el Decreto 594 de 2015 señala que el Plan de Movilidad Escolar para Bogotá, tiene como objetivo general educar, formar y proteger a la comunidad escolar frente a sus desplazamientos desde y hacia los establecimientos educativos, en medios motorizados y no motorizados.

Sin mencionar nada al respecto de la movilidad en zonas rurales.

Respecto al servicio de salud, se evidencia que no es satisfactorio, ya que para las personas que viven el territorio y la escuela, conseguir las citas y los medicamentos lleva mucho tiempo. Esto afecta algunas dinámicas de la escuela, así lo expresa la docente de Necesidades Educativas Especiales:

para el ingreso o matrícula aquellos niños y niñas que presentan alguna condición de discapacidad deben presentar un certificado médico, cuando ingresan con este proceso adelantado, desde el inicio del año se prepara un programa flexible para estas situaciones. La verdad en la mayoría de los casos no sucede, puesto que muchas familias no tienen acceso a salud y cuando se inicia el trámite por solicitud o remisión de la institución educativa, el trámite es demorado y se pierde tiempo valioso de los procesos con las niñas y niños (comunicación personal, 20 de septiembre del 2019).

El Decreto 1421 de agosto 29 de 2017, en su Artículo 2.3.3.5.2.3.3. "Acceso al servicio educativo para personas con discapacidad", numeral 1, expone:

El estudiante con discapacidad que se encuentra en proceso de ingreso al sistema educativo formal deberá contar con diagnóstico, certificación o concepto médico sobre la discapacidad emitida por el sector salud y con el PIAR o el informe pedagógico si viene de una modalidad de educación inicial, que permita identificar el tipo de discapacidad. En caso de que el estudiante no cuente con dicho requisito, se deberá proceder con la matrícula y con el registro de las variables para la identificación de los estudiantes con discapacidad en el SIMAT, con base en la información de la familia y se efectuará el reporte correspondiente a la respectiva secretaría de educación, o entidad que haga sus veces, para que en articulación con el sector salud se establezca el diagnóstico y el proceso de atención más pertinente, en un plazo no mayor a tres meses.

\section{La escuela como territorio vivido}

Vincula pensamientos y sentimientos sobre la visión generalizada de lo urbano y lo rural de manera colectiva y prejuiciosa en medio de la dicotomía-. Este criterio apela a experiencias individuales como el hecho de que la escuela es el punto de encuentro para los pobladores de la vereda, ya sea porque el salón comunal queda ahí mismo, o por el uso de la cancha deportiva; mientras que para la mayoría de la tersitarios 44 Especial 
comunidad educativa tiene que ver con el lugar donde se desarrolla una función. Uno de los puntos de encuentro y relación, es la crítica y desacuerdo frente al criterio de lo legal. La escuela como territorio vivido (figura 5) responde, entonces, al sentimiento de pertenencia de docentes, administrativos y personal de servicios generales; también a percepciones positivas o negativas. Por ejemplo, la cercanía al relleno sanitario es símbolo de insalubridad, la distancia y dificultad en el acceso generan una percepción de exclusión y de olvido, como si se invisibilizara esa parte de la ciudad. Con esto, se cuestiona la escuela legal por el incumplimiento de su normativa y por la inequidad que es evidente en las instituciones rurales a partir de lo declarado por las personas en tanto insatisfacciones y sensación de invisibilización, también al desconocer las dinámicas de una población que se reduce cada vez más.

El Decreto 327 de 2007, expuesto en los Lineamientos Educativos para la Bogotá Rural, Política Pública Distrital de Ruralidad, propone 4 ejes de integración entre el territorio rural y el urbano: (1) Territorialidad, (2) Desarrollo humano sostenible, productividad y seguridad alimentaria, (3) Identidad y culturas campesinas y, (4) Institucionalidad democrática. tersitorias 44 Especial 76
Figura 5. Muestra ejercicio de representación

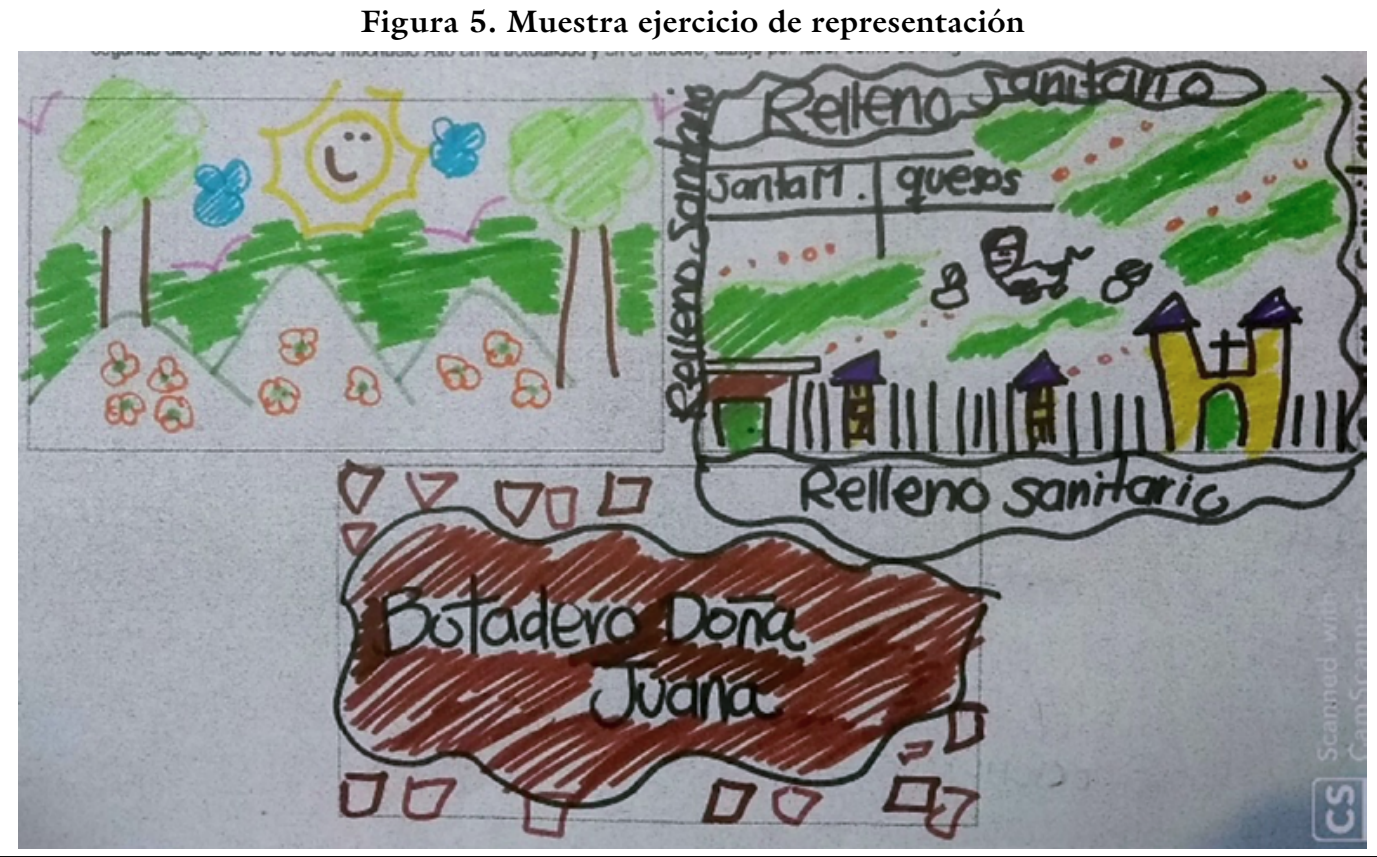

Nota: taller con maestras y maestros del Colegio Rural Mochuelo Alto, sobre representaciones de la escuela como territorio desde lo subjetivo y lo colectivo (2019). Fuente: elaboración propia.

Francy Yulieth Gómez T., Edier Hernán Bustos V., Jaime Duván Reyes R. 
Cada uno de estos ejes tiene que ver con el equipamiento territorial con relación a la escuela y con la garantía de los derechos de niños, niñas y comunidad en general, es decir, que están orientados por lo ambiental, lo económico, lo social, lo cultural y lo político.

Se plantea una lectura crítica de varios factores que construyen una idea frente a situaciones en el marco de la desigualdad, la injusticia, la inequidad y la pobreza con la que se ha asociado el territorio rural. La desconexión con el centro, aludiendo a lo periférico, supone un dominio de la informalidad (García Canclini, 2004) y un juicio que descalifica, en este caso, la ubicación del relleno carga de prejuicios que señalan al corregimiento, a las veredas y a la institución educativa.

\section{La escuela como territorio pensado}

Representa un desencuentro entre las comunidades educativa y de la vereda (figura 6), no de forma generalizada, pero sí parcialmente, ya que la construcción social e histórica que tienen los habitantes de la vereda dista de los y las docentes de la escuela, pues la mayoría de estos últimos no comparte la construcción de los primeros. Dicha distancia puede evidenciarse en un trato estereotipado o en prejuicios que

Figura 6. Mapeo de la institución educativa rural

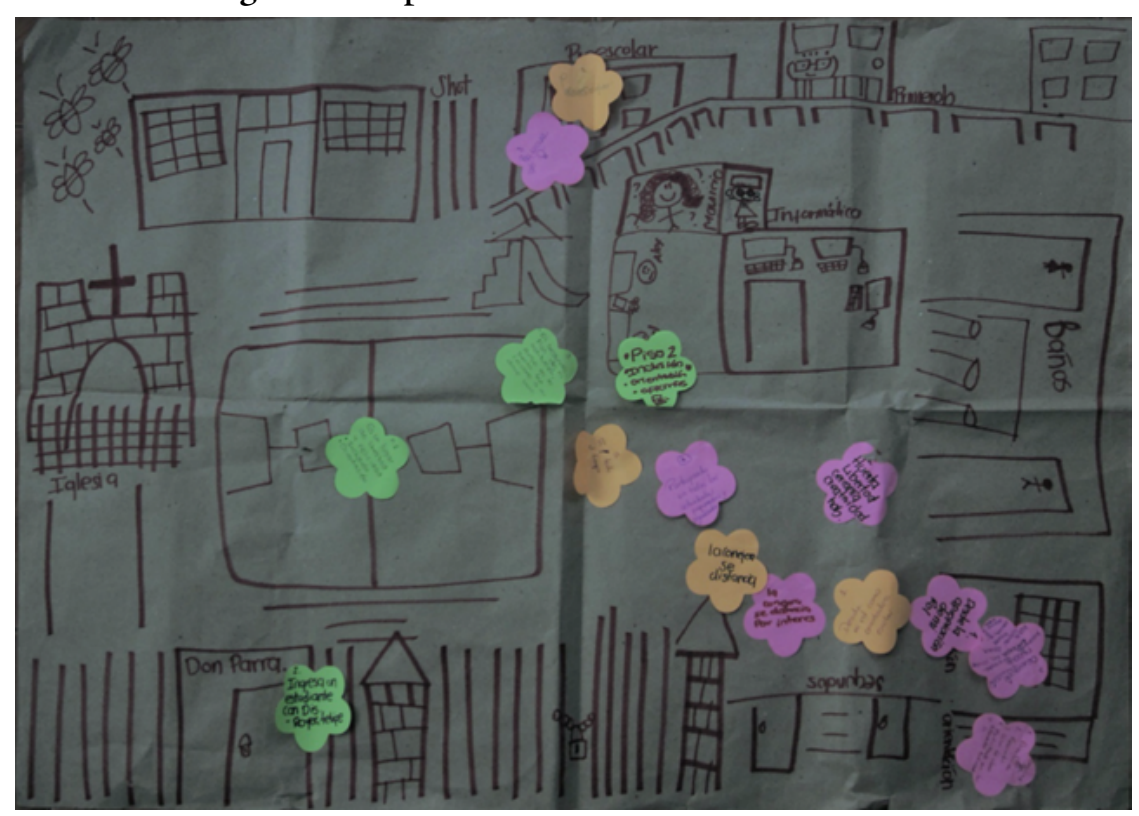

Nota: taller con maestras y maestros del Colegio Rural Mochuelo Alto, sobre representaciones de la escuela como territorio desde lo subjetivo y lo colectivo (2019). Fuente: elaboración propia. 
generalizan la percepción dicotómica entre campo y ciudad. Sin embargo, desde el criterio de lo real, siguen existiendo puntos de encuentro que generan un pensamiento colectivo tras las exigencias de inclusión, equidad y participación.

\section{La escuela como territorio legal}

Convoca a las comunidades en una desaprobación frente a las acciones de sanción del RSDJ, así como en un desconocimiento respecto de las acciones legales para direccionar su inconformidad con el funcionamiento del relleno, pues los espacios de formación y participación son reducidos (figura 7). Se comparte la insatisfacción hacia las leyes que deberían garantizar el bienestar de las comunidades que se ven afectadas por la deficiencia en las operaciones al interior del vertedero.

En el diagnóstico comunitario Ciudad Bolívar, publicado por la Defensoría del Pueblo en el Territorio 2018, en su apartado sobre derechos ambientales y colectivos, luego del diagnóstico y el análisis de la información expone:

La vereda Mochuelo presenta riesgo antrópico y contaminación atmosférica, debido a la explotación de canteras, chimeneas de industria, mataderos clandestinos y el Relleno Sanitario Doña Juana, todo lo cual puede generar material particulado y gases además de olores ofensivos (p. 61). tersitarios 44 Especial
Figura 7. Mapeo de la vereda Mochuelo Alto con estudiantes

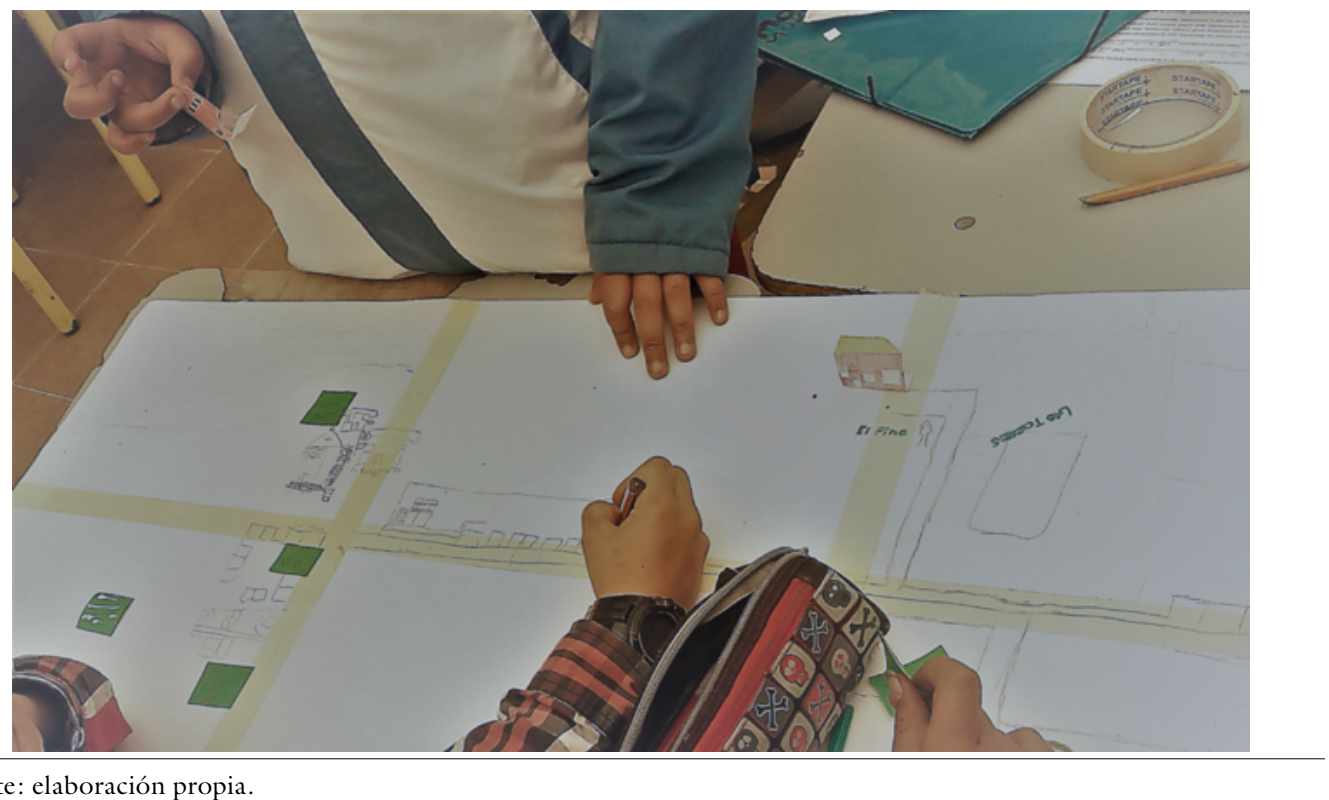

Fuente: elaboración propia. 
El Ministerio de Ambiente y Desarrollo Sostenible emitió la Resolución 1484 del 3 de Agosto de 2018, “por la cual se asume la competencia del proyecto sanitario Doña Juana" y se toman otras determinaciones. En la resolución se presentan los incumplimientos en materia ambiental: no se realizan los monitoreos ambientales requeridos, no se han construido hasta la fecha los tres desarenadores exigidos, solo se ha realizado la prueba de una de las bombas de agua subterráneas y no se ha terminado la construcción del dique ambiental sur; de los seis pozos de monitoreo de agua subterráneos solo se han instalado dos, el vertimiento de lixiviados tratados realizado al río Tunjuelo no cumple los parámetros y se observan deficiencias en la cobertura temporal de la zona de disposición.

Ante estas situaciones se han puesto sanciones económicas, pero el relleno sigue funcionando y afectando a la comunidad de la vereda y de la institución educativa rural, como se puede ver en la página oficial de la Personería de Bogotá, ${ }^{5}$ en la que se manifiesta:

Después de 4 veedurías, decenas de visitas técnicas y administrativas en los últimos años y múltiples reuniones [...] el Distrito sigue permitiendo que el concesionario haga caso omiso a las obligaciones [...] respetando el derecho a un ambiente sano para los capitalinos, especialmente de los habitantes del sector (párr. 7).

\section{La escuela como territorio posible}

Centra las dinámicas relacionales de las comunidades en el intercambio de saberes o procesos de co-construcción que aportan, para el caso de esta investigación, tanto a la Institución Educativa Rural Mochuelo Alto, como a la comunidad de la vereda (figura 8). Cuando se genera la comprensión territorial, a partir de compartir las diferentes miradas, experiencias y saberes que se tienen del espacio ocupado, y además, se generan acciones transformadoras, esos territorios soñados de carácter individual se convierten en posibilidades colectivas de desarrollo.

Figura 8. Diagrama explicativo de relaciones

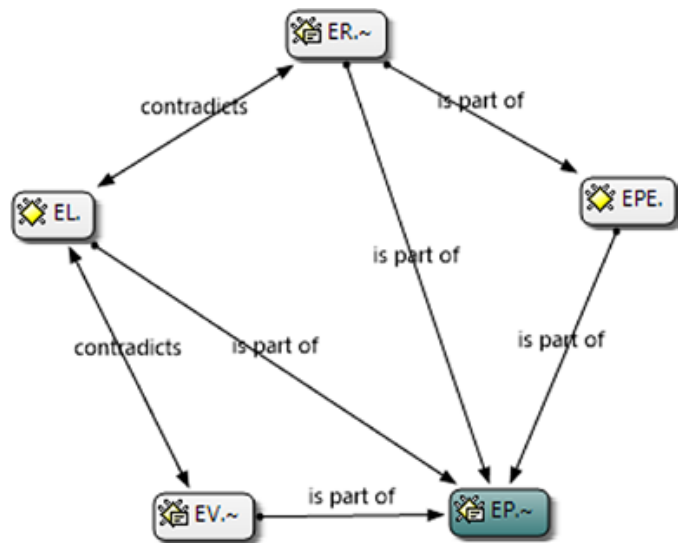

Fuente: elaboración propia a partir de Atlas-ti®.

El trabajo de co-construcción que se desarrolló en esta investigación, inició durante los encuentros con diferentes personas que integran las comunidades de la vereda Mochuelo Alto y la Institución
5 https://www.personeriabogota.gov.co/sala-deprensa/notas-de-prensa/ item/574-uaesp-le-da-laespalda-al-relleno-donajuana

\section{territarias 44 Especial}




\section{tersitarios} 44 Especial
Educativa Rural Mochuelo Alto. Sus lecturas alrededor de lo que se ha denominado la escuela como territorio evidencia las miradas de familias, vecinas y vecinos de la escuela, las maestras, maestros, directivos, guardas de seguridad y equipo del cuidado o de servicios generales; la sistematización de estas lecturas se recogió a través de ejercicios cartográficos, mapeos, representaciones, entrevistas y talleres. La información recopilada no solamente es acerca de los lugares, sino de las relaciones que se establecen desde las categorías del territorio bajo el concepto de escuela, las cuales se alimentan de las experiencias particulares y conocimientos adquiridos de vivir, trabajar y conocer el territorio.

Al desarrollar los ejercicios de mapeo y cartografía se construyeron las herramientas de análisis con las comunidades, quienes, al lado de la maestra rural, y luego junto a las comunidades del equipo de investigación, harán uso de estas herramientas para el análisis, discusión y reflexión, en aras de construir unas acciones de posibles cambios o transformaciones.

El aporte metodológico de esta investigación al fusionar elementos de la investigación cualitativa de tipo descriptivo, con un enfoque de inteligencia territorial usando el método de la investigación acción y la propuesta de Territorii como estrategia, promueve, por un lado, diversas maneras de interactuar con las comunidades en un despliegue de posibilidades de trabajo para desarrollar planes de acción a partir del conocimiento popular y las experiencias de los sujetos y, por otro, la equidad frente al conocimiento. Además, muestra a la investigadora principal inmersa en la sociedad, no como un ser distante de la comunidad, sino como una mujer, maestra que la estudia y participa junto a ella para transformarla.

Al caracterizar los rasgos de la correspondencia entre la comunidad de la vereda y la comunidad educativa, teniendo en cuenta las diversas territorialidades que convergen en la escuela rural con distintos intereses, percepciones, actitudes y comunicación territorial, se denominan las relaciones a partir de la cooperación, la complementariedad y el conflicto (Montañez et al., 1998).

Se llegó a la comprensión de una relación que surge a partir del conflicto que genera la fragmentación del poder en medio de una espaciación, ya que la intrusión del relleno y las formas en que opera son evidencia de la falta de presencia estatal, pero además, de un poder y control económico y del espacio por parte del RSDJ. El poder con el que se reconoce a la institución educativa distrital rural por su ubicación (frontera simbólica de contención) y saber desde la academia y, el poder que tienen los habitantes de la vereda por sus conocimientos y saberes de la tradición campesina, del territorio y usos del suelo rural.

Se han reconocido acciones de complementariedad y apoyo, pero son pasajeras y carecen de una reflexión o proyección para la organización de acciones concretas, 
pues la mayoría de ellas convergen en los encuentros entre las comunidades por la exigencia de la presencia estatal en una solicitud por equidad, calidad en los servicios de salud, transporte y todo lo relacionado al equipamiento de la zona rural. En este sentido, el poder local que ejerce el RSDJ ha tenido que coexistir con poderes disidentes: la escuela y la vereda Mochuelo Alto.

Bajo la denominación de cooperación en el análisis de las relaciones, la cooperación es una forma de relacionarse que se vincula a los territorios posibles, es decir, surge como propuesta, como posibilidad para lograr el encuentro, reconocimiento y trabajo de co-construcción entre las comunidades de la institución educativa y de la vereda Mochuelo Alto.

\section{Reterritorialización de la escuela rural}

Para efectos de esta investigación, el concepto de reterritorialización no es el que se reduce a los discursos globalizados y globalizantes que la enmarcan en oposición a la desterritorialización, sino que se entiende en el sentido de Beatriz Nates Cruz - al referirse a García Canclinien su texto Soportes teóricos y etnográficos sobre conceptos de territorio (2010), es decir, como relocalizaciones territoriales que pueden ser relativas parcialmente a

Figura 9. Mesas de trabajo

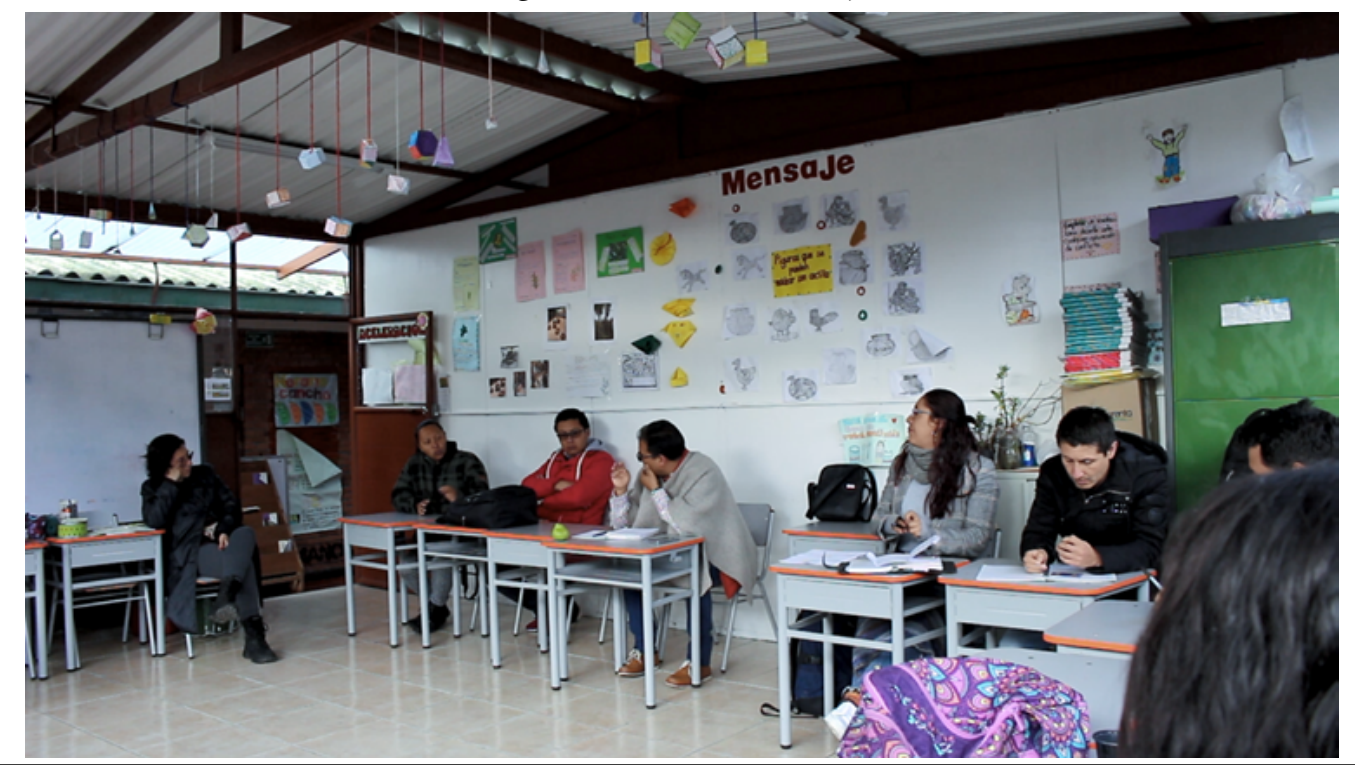

Nota: taller con maestras y maestros del Colegio Rural Mochuelo Alto sobre representaciones de la escuela como territorio desde lo subjetivo y lo colectivo (2019). Fuente: elaboración propia. 


\section{territarios} 44 Especial viejas y nuevas producciones simbólicas (p. 216). En tal sentido, las mesas de trabajo (figura 9) permitieron reconocer que la reterritorialización del Colegio Rural Mochuelo Alto se da por la participación de diferentes, diversas y desiguales territorialidades que participan de su configuración histórica, las cuales se conforman por un carácter movible y mudable de sus agentes participantes.

Por configuración histórica, se hace referencia a todos los procesos de apropiación espacio-temporal de carácter simbólico y material. En los territorios hay agentes decisores que convocan a la actuación en conjunto y de forma solidaria por la redefinición del espacio sobre las acciones y decisiones de las comunidades. Esta actividad espacial va buscando coherencia en sus acciones cotidianas y merece toda una resignificación de las prácticas, lo cual conlleva a que la resignificación no trasforme solamente las acciones de los agentes territoriales, sino incluso, sus otros espacios, aquellos que físicamente son distantes a los del territorio de la institución educativa. Es decir que pasamos de lo subjetivo a lo colectivo, porque como institución educativa distrital rural, el Colegio Mochuelo Alto puede generar acciones de carácter colectivo, acciones concretas de microtransformación.

\section{Conclusiones}

Durante el desarrollo de la investigación se generaron espacios de encuentro y diálogo alrededor de la percepción que se tenía de las relaciones entre quienes hacen parte de la institución y quienes habitan la vereda. Después de participar en los diferentes espacios y con los diferentes actores de las comunidades, se desarrolló una mesa de trabajo territorial en la cual se llevan todos los resultados de los diferentes encuentros con los y las participantes, los mapas elaborados sobre la escuela, la vereda, las entrevistas, los dibujos y representaciones. De esta manera, se realizó una descripción del proceso entre los y las asistentes a la mesa, hubo un trabajo de clasificación de información a la par de la participación sobre los temas expuestos y de conexión frente a sus propios saberes y conocimientos, por lo que al finalizar se proyectaron una serie de acciones para el 2020. Estas son:

- La huerta para todas las prácticas acompañadas por familias y docentes.

- Proyectos de aula que sean socializados mensualmente con todos los grados, para ampliar el conocimiento y comprensión acerca de las problemáticas y las posibilidades de transformación que existen en el territorio y con sus habitantes.

- Biblioteca pública y escolar que acompañe procesos de lectura, escritura y arte.

- Espacios de participación y recorridos por el corregimiento. Es necesario hacer alianzas intersectoriales. Hay universidades que están haciendo 
investigaciones en la zona y hay que empezar a articular los intereses de las universidades con las necesidades y propuestas de la comunidad de Mochuelo.

- Directorio de oficios y saberes de las personas de la vereda.

Estos cinco puntos se incluyeron en la agenda de trabajo del Comité de Gestión, junto con la comunidad. A partir del 2020, el comité se constituyó en el Colegio Rural Mochuelo Alto y tiene como objetivo propiciar los espacios de encuentro, reflexión, planeación y gestión con las comunidades para el desarrollo de proyectos. Dos de ellos han sido propuestos hasta el momento: Hacia el reconocimiento $y$ apropiación del territorio rural desde las prácticas agro-ecológicas significativas con la comunidad en el CED Rural Mochuelo Alto (PRAE) y, el de educación para la justicia, la paz, la democracia, la solidaridad, la confraternidad, el cooperativismo y la formación de valores y en derechos humanos: Mochuelo en tiempos de paz para la reconciliación con el territorio. Hacer posibles esas proyecciones y cumplir con la agenda propuesta, requiere de un gran compromiso, solidaridad, trabajo colaborativo, ética, voluntad política y reconocimiento de los saberes de las comunidades.

Teniendo en cuenta lo reflexionado hasta el momento desde el enfoque territorial (Santos, 2000) y las categorías del método Territorii (Bozzano, 2009a), se comprende a la Institución Educativa
Rural Mochuelo Alto como un territorio que media en la construcción social. Para el caso de Bogotá, es un espacio socialmente construido desde las territorialidades rurales, urbanas y de borde o periurbanas. Es un espacio multidimensional en el que se dinamizan relaciones transterritoriales y transtemporales (Saquet, 2015).

Las relaciones transterritoriales y transtemporales se han experimentado en los procesos resultados del periodo de cuarentena por la contingencia, frente a la presencia del COVID-19 en Colombia; estas radican en el contacto que la escuela ha tenido con las familias que integran la comunidad educativa y, de alguna manera, con los habitantes del corregimiento permitiendo que haya una identificación a partir de una relación de carácter educativo. A causa de la contingencia se tuvo que postergar la agenda propuesta al comité, sin embargo, se continúa en la construcción del documento sobre la organización del comité de gestión con la comunidad y apoyando todas las propuestas que surgen desde la dirección rural del colegio en las que es fundamental el enfoque territorial.

\section{Referencias}

Alcaldía Local de Ciudad Bolívar. (s.f.). Conociendo mi localidad. Alcaldía Mayor de Bogotá. http://www.ciudadbolivar. gov.co/mi-localidad/conociendo-milocalidad/historia

Alcaldía Local Ciudad Bolívar \& Secretaría Distrital de Ambiente. (2016). territarios 44 Especial 


\section{territorias 44 Especial} 84
Plan ambiental local. Localidad 19 Ciudad Bolivar 2013-2016. Alcaldía Mayor de Bogotá. http:// www.ambientebogota.gov.co/ documents / $10157 / 2883179 /$ $\mathrm{PAL}+\mathrm{CBol} \% \mathrm{C} 3 \% \mathrm{ADvar}+2013-2016$. pdf

Bozzano, H. (2009a, 4-7 de noviembre). Territorios: El Método Territorii. Una mirada territorial a Proyectos e investigaciones no siempre territoriales [Conferencie]. 8th International Conference of Territorial Intelligence. ENTI. Salerno, Italia. https://halshs.archives-ouvertes.fr/halshs-00533337/document Bozzano, H. (2009b). Territorios posibles. Procesos, lugares y actores. Lumiere.

Bozzano, H. (2012). Territorios Reales, Territorios Pensados y Territorios Posibles. Aportes para una teoría territorial del ambiente. Espacio Editorial.

Bozzano, H. (2017). Territorios posibles y utopías reales. Aportes a las teorías de la transformación: inteligencia territorial y justicia territorial. Colombia. Arquetipo, (15), 71-92. https://revistas.ucp. edu.co/index.php/arquetipo/article/ view/184

Bustos Velazco E., \& Molina Andrade A. (2019). Concepciones de territorio en profesionales de las Ciencias de la tierra. Universidad Distrital Francisco José de Caldas.

Cruz Casallas, S., \& Pachón Ramírez, O. (2010). Propuesta de un modelo de una asociación de agricultores y ganaderos de la Vereda Mochuelo Alto
(Tesis de pregrado). Universidad de La Salle. https://ciencia.lasalle.edu.co/ administracion_de_empresas/786/

Defensoría del Pueblo Colombia. (2018). Diagnóstico comunitario Ciudad Bolivar. La defensoría del Pueblo en el Territorio.

García Canclini, N. (2004). Diferentes desiguales y desconectados. Mapas de la Interculturalidad. Gedisa Editorial.

Méndez, F., Gómez, O., Girón, S., Mateus, J., Mosquera, J., Filigrana, P.,... \& Gulloso, L. (2006). Evaluación del impacto del relleno sanitario Doña Juana en la salud de grupos poblacionales en su área de influencia. Grupo Epidemiología y Salud Poblacional; Universidad del Valle.

Montáñez, G., \& Mahecha, O. D. (1998). Espacio, territorio y región: conceptos básicos para un proyecto nacional. Cuadernos de geografía: Revista colombiana de geografía, 7(1-2), 120134.

Pedraza, M. (2017). Caracterización Mochuelo Alto. Una Nueva Mirada.

Santos, M. (2000). La naturaleza del espacio. Técnica y tiempo. Razón y emoción. Editorial Ariel.

Saquet, M. (2015). Por una geografía de las territorialidades y las temporalidades: Una concepción multidimensional orientada a la cooperación y el desarrollo territorial. Universidad Nacional de La Plata.

Secretaría Distrital de Ambiente. (2011). Plan de Investigación Ambiental de 
Bogotá 2012- 2019. Dirección de Planeación y Sistemas de Información Ambiental. http://ambientebogota.gov.co/es/c/document_library/ get_file? uuid $=$ b502db9c-a248-4f68bd07-54f30f628691\&groupId $=101$ 57 Bogotá.

Secretaría Distrital de Planeación. (2019, 20 de noviembre). Formulación de la revisión general del POT de Bogotá D.C. Alcaldía de Bogotá. http://www.sdp. gov.co/micrositios/pot/proyecto-deacuerdo 